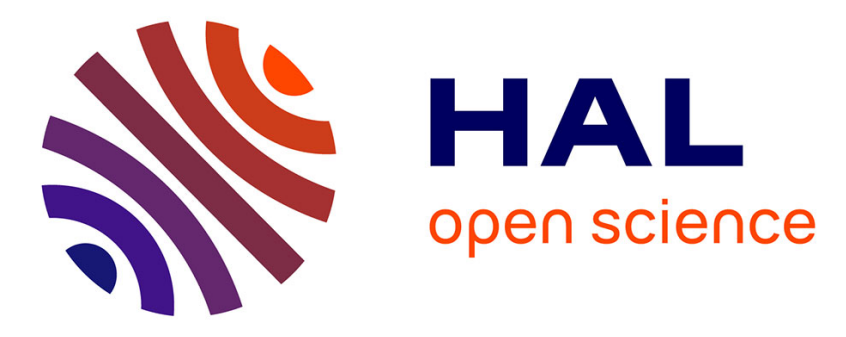

\title{
Application of a SUGAR model to analyse sugar accumulation in peach cultivars that differ in glucose-fructose ratio
}

B.H. Wu, Bénédicte Quilot-Turion, Michel M. Génard, S.H. Li, J.B. Zhao, J. Yang, Y.Q. Wang

\section{To cite this version:}

B.H. Wu, Bénédicte Quilot-Turion, Michel M. Génard, S.H. Li, J.B. Zhao, et al.. Application of a SUGAR model to analyse sugar accumulation in peach cultivars that differ in glucose-fructose ratio. Journal of Agricultural Science, 2012, 150, pp.53-63. 10.1017/S0021859611000438 . hal-02644745

\section{HAL Id: hal-02644745 \\ https://hal.inrae.fr/hal-02644745}

Submitted on 28 May 2020

HAL is a multi-disciplinary open access archive for the deposit and dissemination of scientific research documents, whether they are published or not. The documents may come from teaching and research institutions in France or abroad, or from public or private research centers.
L'archive ouverte pluridisciplinaire HAL, est destinée au dépôt et à la diffusion de documents scientifiques de niveau recherche, publiés ou non, émanant des établissements d'enseignement et de recherche français ou étrangers, des laboratoires publics ou privés. 
Application of a SUGAR model to analyse sugar accumulation in peach cultivars that differ in glucose-fructose ratio

Short title: Analysis of sugar accumulation in peaches

B. H. WU ${ }^{1, *}$, B. QUILOT ${ }^{2}$, M. GÉNARD ${ }^{3}$, S. H. $\mathrm{LI}^{1}$, J. B. ZHAO ${ }^{4}$, J. YANG ${ }^{1}$ AND Y.

$$
\text { Q. WANG }{ }^{1}
$$

${ }^{1}$ Institute of Botany, Chinese Academy of Sciences, 100093 Beijing, China

${ }^{2}$ UR1052, Génétique et Amélioration des Fruits et Légumes, INRA, BP 94, 84143

Montfavet, France

${ }^{3}$ UR1115 Plantes et Systèmes de culture Horticoles, INRA, F-84000 Avignon, France

${ }^{4}$ Institute of Forestry and Fruit, Beijing Academy of Agriculture and Forestry

Sciences, 100094 Beijing, China

(Received 7 June 2010, revised 25 November 2010 \& 23 February 2011, accepted 24

March 2011)

\section{SUMMARY}

A SUGAR model, which was established to predict the partitioning of carbon into sucrose, glucose, fructose and sorbitol in fruit mesocarp of peach cultivars (Prunus persica (L.) Batch) with normal glucose:fructose ratio (G:F) of 0.8-1.5, was evaluated and extended for peach cultivars with a high G:F ratio of 1.5-7.8. The extended model (SUGARb) is more generic and assumes a high G:F ratio to be due to preferential transformation of sorbitol into glucose, preferential utilization of fructose, or

\footnotetext{
* To whom all correspondence should be addressed. E-mail: bhwu@ibcas.ac.cn
} 
preferential conversion of fructose into glucose. The simulated seasonal variations in sugars via the SUGARb model matched experimental data for three normal and three high G:F cultivars well, and accurately exhibited G:F ratio characteristics. The relative rates of sucrose transformation into glucose and fructose differed according to cultivar but not to G:F status. Compared with hexosephosphate interconversion, a lower production rate of fructose than glucose from sorbitol, and/or a higher utilization rate of fructose than that of glucose might be preferential alternatives for forming high G:F ratios in the high G:F cultivars studied in the present study, which is discussed in the light of recent results on enzyme activities.

\section{INTRODUCTION}

The sweetness and taste of fruit are highly dependent on sugar composition, because sugars differ in their relative sweetness (Kulp et al. 1991). If sucrose is rated 1.0 in terms of sweetness, fructose is rated about 1.75 , glucose 0.75 and sorbitol 0.5 (Pangborn 1963; Doty 1976). In peach fruit, sucrose predominates followed by the reducing sugars (glucose and fructose) and sorbitol (Moriguchi et al. 1990a; Robertson et al. 1990).

It has been reported that the glucose and fructose contents of peach fruit are similar (Lo Bianco et al. 1999; Morandi et al. 2008; Moriguchi et al. 1990a; Vizzotto et al. 1996). For example, Esti et al. (1997) reported similar levels of glucose and fructose in mature fruit of 21 peach and nectarine cultivars, as did Dirlewanger et al. (1999) using mature fruit of 63 F2 genotypes from a cross between the non-acid peach 
'Ferjalou Jalousia ${ }^{\circledR}$ ' and the acid nectarine 'Fantasia'. Glucose and fructose contents were also found to be approximately equal during peach fruit development and exhibited similar patterns of seasonal variation (Chapman \& Horvat 1990; Génard et al. 2003). However, compared with market-quality cultivars, a lower amount of fructose in native and flowering peaches was reported by Moriguchi et al. (1990b). In a previous report, fructose concentration was found to be about a quarter that of glucose in 17 of 107 peach genotypes, derived from a clone of a wild peach $(P$. davidiana) and three generations of crosses with commercial nectarine cultivars (Wu et al. 2003).

These observations indicate that some genotypes behave differently with respect to production and/or utilization of fructose and glucose, even though glucose and fructose have similar molecular structures, are simultaneously produced by degradation of sucrose, and are highly inter-convertible in growing fruit. To date, very little is known regarding the mechanisms that regulate the balance between glucose and fructose concentrations in peach fruit. Kanayama et al. (2005) suggested that $\mathrm{NAD}^{+}$-dependent sorbitol dehydrogenase $\left(\mathrm{NAD}^{+}-\mathrm{SDH}\right)$ was likely to be responsible for the regulation of fructose concentration in peach fruit. Studies in tomato (Kortstee et al. 2007) and peach (Borsani et al. 2009) have also shown possible different rates of utilization of glucose and fructose, and unbalanced inter-conversion between glucose and fructose.

Because chains of metabolic processes and diverse mechanisms affect fruit sugar content, and because these are under the influence of environmental factors, 
development of quality traits, including sugar content, is poorly understood. Given the complexity of the processes, modelling may help to elucidate factors governing sugar accumulation or direct the design of experimental optimization strategies and fruit production. For example, a kinetic model was used to investigate detailed metabolic control of sucrose accumulation in maturing sugarcane culm tissue (Rohwer \& Botha 2001; Uys et al. 2007). A SUGAR model was established by Génard \& Souty (1996) to predict the partitioning of carbon into sucrose, sorbitol, glucose and fructose in the mesocarp of peach fruit, and to determine the relative rates of sugar transformation. However, this model needs to be tested in response to genetic diversity and environmental conditions to make it more generic. First, the SUGAR model was applied to a single peach cultivar, cvar Suncrest, with similar glucose $(G)$ and fructose (F) concentrations (normal G:F), and simulated changes in sugar concentrations during the final rapid growth stage of peach (Génard \& Souty 1996; Génard et al. 2003). Subsequently, it was simplified to analyse genotypic variation in total sugar content and refractometric index in peach fruit flesh (Grechi et al. 2008; Quilot et al. 2004), and was modified to simulate seasonal variations in sucrose, glucose and fructose concentration in apricot cvar Bergeron (Génard et al. 2006). In the present case, a more generic model needs to be developed to describe cultivars with high G:F ratio. Indeed, the SUGAR model relied on constraining assumptions, including similar utilizations rates of glucose and fructose for synthesis of other compounds, and equivalent inter-conversion rates between glucose and fructose (Génard \& Souty 1996; Génard et al. 2003). 
In the present study, genetic diversity of three peach cultivars with normal G:F, as well as three peach cultivars with lower fructose than glucose concentration (high G:F), were explored. The SUGAR model was modified to take into account specific utilization rates of glucose and fructose to form other compounds, and an unbalanced transformation rate between glucose and fructose, which were not considered before in the SUGAR model. Thus, together with different degradation rates of sorbitol to glucose and fructose (already described in the SUGAR model), the three possible pathways that could result in different concentrations of glucose and fructose were compared to gain insights into the mechanism(s) regulating glucose and fructose accumulation in peach fruit.

\section{MATERIALS AND METHODS}

\section{Plant materials}

Based on G:F values in mature peach flesh obtained from a previous study in 2003 (Niu et al. 2006) and 2004 (data not shown), six cultivars with two contrasting G:F ratios were chosen to investigate seasonal variations of sugars, especially glucose and fructose. In 2005, three normal G:F peach cultivars, Shanyibaitao, Yanhong and Gangshanbai, and three high G:F peach cultivars, Zhanghuang 7, Long 246 and Linbai 7, were studied. Except for cvar Linbai 7, the other five cultivars were also studied in 2007. All trees were grown at the National Field Gene Bank of Peach and Strawberry, Institute of Forestry and Fruit, Beijing Academy of Agriculture and Forestry Sciences (north latitude 39.9", east longitude 116.3", $60 \mathrm{~m}$ asl). They were 
6-9 years old, and received normal management practices for commercial production, such as fertilization, pruning, thinning and irrigation. Fruits were sampled randomly every 1-2 weeks during the final rapid growth stage until maturity. Depending on cultivar, sampling occurred from Jul 11 (74-85 days after bloom, DAB) to maturity Aug 18-Sept 1 (124-138 DAB) in 2005 and from July 8 (82-83 DAB) to maturity Aug 20 (125-126 DAB) in 2007. Sampling was replicated four times, each replicate consisting of two fruits.

\section{Fruit and sugar measurements}

At each harvest and for each replicate, mesocarp fresh weight was measured. A part of the fresh mesocarp was then weighed, and dry weight was determined after drying at $70{ }^{\circ} \mathrm{C}$ for $72 \mathrm{~h}$. The remaining fresh mesocarp was sliced, immediately frozen in liquid nitrogen and stored at $-70{ }^{\circ} \mathrm{C}$ prior to sugar analysis.

For sugar analysis, $1 \mathrm{~g}$ of mesocarp tissue was ground to a fine powder with a pestle and mortar, and extracted three times with $6 \mathrm{ml}$ double-distilled water. After centrifugation at $2000 \mathrm{~g}$ for $10 \mathrm{~min}$, the supernatants were decanted, passed through a SEP-C18 cartridge (Supelclean ENVI C18 SPE), and filtered through a $0.22 \mu \mathrm{m}$ filter.

Sucrose, sorbitol, glucose and fructose were determined by high performance liquid chromatography (HPLC, Dionex P680; Dionex Corporation, CA, USA). Sugars were detected by a Shodex RI-101 refractive index detector with reference cell maintained at $40{ }^{\circ} \mathrm{C}$. A Transgenomic CARB Sep Coregel $87 \mathrm{C}$ column $(300 \mathrm{~mm} \times 7.8 \mathrm{~mm}$ i.d., 10 $\mu \mathrm{m}$ particle size) with a guard column cartridge (Transgenomic CARB Sep Coregel 
87C cartridge) was used. The column was maintained at $85{ }^{\circ} \mathrm{C}$ with a Dionex TCC-100 thermostated column compartment. Degassed, distilled, deionized water at a flow rate of $0.6 \mathrm{ml} / \mathrm{min}$ was used as the mobile phase. The injection volume was $10 \mu \mathrm{l}$. The Chromeleon chromatography data system was used to integrate peak areas according to external standard solution calibrations.

Daily average temperatures were monitored at a weather station near the study site.

\section{Description of the model}

A simplified representation of sugar metabolism in fruit (the SUGAR model) was based on apple (Berüter et al. 2004) and is shown in Fig. 1a. In the Rosaceae family, which includes peach and apple, sorbitol and sucrose are the main assimilates transported in the phloem (Moing et al. 1997). Sugar accumulation during peach fruit growth is mainly from the import of sorbitol and sucrose from photosynthesis in leaves, which is unloaded and enters a number of metabolic pathways. Sorbitol is converted into fructose by $\mathrm{NAD}^{+}$-dependent sorbitol dehydrogenase $\left(\mathrm{NAD}^{+}-\mathrm{SDH}\right)$, and into glucose by sorbitol oxidase (SOX). Sucrose is hydrolysed into glucose and fructose by acid invertase, neutral invertase and sucrose synthase. Glucose and fructose are converted by hexokinase (HK) and fructokinase (FK), respectively, to glucose-6-phosphate (Glu6P) and fructose-6-phosphate (Fru6P), which are further used as substrates for glycolysis and synthesis of compounds other than sugars (e.g. starch, acids, structural carbohydrates and protein). Phosphoglucose isomerase (PGI) can reversibly convert Glu6P and Fru6P. 
Based on sugar metabolic reactions (Fig. 1a), the SUGAR model assumed: i) the fruit behaved as a single metabolic compartment with all sugars available for metabolism during the final rapid stage of peach fruit growth; ii) phloem carbon was unloaded only as sucrose and sorbitol; iii) conversion of sucrose yielded equal quantities of glucose and fructose; and iv) carbon used for respiration and synthesis of other compounds only came from glucose and fructose. Compared with the SUGAR model, the modified model referred to as SUGARb (Fig. 1b) considers distinct utilization rates of glucose and fructose to form other compounds, and an unbalanced transformation rate between glucose and fructose.

Thus, in the SUGARb model carbon transformations can be described with the following transformation rates: $k_{1}(t)$ (/day) is net sucrose transformation to glucose and fructose; $k_{2}(t)$ (/day) is net sorbitol transformation to glucose; $k_{3}(t)$ (/day) is net sorbitol transformation to fructose; $k_{4}(t)$ (/day) and $k_{5}(t)$ (/day) are net glucose and fructose transformations, respectively, to other compounds; and $k_{6}(t)$ (/day) is net fructose transformation to glucose indirectly through the conversion between Fru6P and Glu6P. In the SUGAR model, $k_{4}(t)$ was assumed to be equal to $k_{5}(t)$, and $k_{6}(t)$ assumed to be null. $\lambda \mathrm{ph}$ (dimensionless) and $1-\lambda \mathrm{ph}$ are the proportions of carbon in the form of sucrose and sorbitol, respectively, from the phloem sugars unloaded into fruit. $\lambda$ ph was set to 0.54 , based on measurements for phloem sap of a peach rootstock (GF305) by Moing et al. (1992).

The carbon fluxes in the forms of sucrose, glucose, fructose and sorbitol in the mesocarp per day $\left(\frac{d M s u}{d t}, \frac{d M g l}{d t}, \frac{d M f r}{d t}, \frac{d M s o}{d t}, \mathrm{~g}\right.$ C/day) in the SUGARb model 
are expressed as follows:

$$
\begin{aligned}
& \frac{d M s u}{d t}=\lambda p h \frac{d M p h}{d t}-k_{1}(t) M s u \\
& \frac{d M g l}{d t}=\frac{k_{1}(t)}{2} M s u+k_{2}(t) M s o-k_{4}(t) M g l-\frac{M g l}{M g l+M f r} \frac{d M r e}{d t}+k_{6}(t) M f r \\
& \frac{d M f r}{d t}=\frac{k_{1}(t)}{2} M s u+k_{3}(t) M s o-k_{5}(t) M f r-\frac{M f r}{M g l+M f r} \frac{d M r e}{d t}-k_{6}(t) M f r \\
& \frac{d M s o}{d t}=(1-\lambda p h) \frac{d M p h}{d t}-\left(k_{2}(t)+k_{3}(t)\right) M s o
\end{aligned}
$$

where $M s u, M g l, M f r$ and $M s o(\mathrm{~g} \mathrm{C})$ are the amount of carbon in the form of sucrose, glucose, fructose and sorbitol in the mesocarp, respectively. $\frac{d M p h}{d t}(\mathrm{~g} \mathrm{C} / \mathrm{day})$ is the carbon flux unloaded from phloem into fruit per day, and $\frac{d M r e}{d t}(\mathrm{~g} \mathrm{C} / \mathrm{day})$ is the carbon flux used for fruit respiration per day, $t$ is the time expressed in days after bloom (DAB).

The amount of carbon in the form of sugar $i$ in the mesocarp (Mi, $i=s u, g l, f r$ and $s o$ ) is calculated:

$$
M i=100 \sigma_{i} C i F W
$$

where $C i$ is the measured concentration of sugar $i(\mathrm{~g} / 100 \mathrm{~g} \mathrm{FW}), F W$ fresh mesocarp weight, and $\sigma_{i}$ the carbon concentration of sugar $i$ (g C/g sugar $i$ ), which are $0.421,0.4$, 0.4 and $0.395 \mathrm{~g} \mathrm{C} / \mathrm{g}$ for sucrose, glucose, fructose and sorbitol, respectively.

Based on Génard et al. (2003), the following equations were chosen to describe metabolic variations with fruit development:

$$
\begin{aligned}
& k_{1}(t)=e^{-k_{1,1}\left(t-k_{1,2}\right)} \\
& k_{2}(t)=k_{2} \\
& k_{3}(t)=k_{3}
\end{aligned}
$$




$$
\begin{aligned}
& k_{4}(t)=k_{4} \frac{1}{D W} \frac{d D W}{d t} \\
& k_{5}(t)=k_{5} \frac{1}{D W} \frac{d D W}{d t} \\
& k_{6}(t)=k_{6}
\end{aligned}
$$

where $D W$ is the daily dry mesocarp weight. $k_{l}(t)$ decreases exponentially with DAB, $k_{1,1}$ is the relative rate of decrease in $k_{1}(t)$, and $k_{1,2}$ is the DAB when $k_{1}(t)=1 /$ day. $k_{2}, k_{3}$ and $k_{6}$ (/day) are transformation rates that remain constant during the experimental period. Since the variables $k_{4}(t)$ and $k_{5}(t)$ are proportional to relative growth rate $\left(\frac{1}{D W} \frac{d D W}{d t}\right)$, parameters $k_{4}$ and $k_{5}$ are dimensionless empirical parameters.

\section{Model inputs and initial conditions}

Daily average temperature and daily mesocarp dry weight were inputs into the SUGARb model. Initial values were mesocarp fresh and dry weight, and sugar concentrations on the first date of the modelled period (about $70 \mathrm{DAB}$ ), and they were used to calculate initial mass of carbon for each sugar.

The respiration flux of carbon $\left(\frac{d M r e}{d t}, \mathrm{~g}\right.$ C/day) was expressed as the sum of maintenance respiration and growth respiration:

$$
\frac{d M r e}{d t}=q_{m} D W Q_{10}^{\frac{T-20}{10}}+q_{g} \frac{d D W}{d t}
$$

where $T\left({ }^{\circ} \mathrm{C}\right)$ is daily mean air temperature, $q_{m}(\mathrm{~g} \mathrm{C} / \mathrm{g} /$ day $)$ is the maintenance respiration coefficient at $20^{\circ} \mathrm{C}, q_{g}(\mathrm{~g} \mathrm{C} / \mathrm{g})$ the growth respiration coefficient, and $Q_{10}$ the temperature ratio of maintenance respiration (dimensionless). Values of $q_{m}, q_{g}$ and 
$Q_{10}$, taken from DeJong et al. (1987) and DeJong \& Goudriaan (1989), are $0.000652 \mathrm{~g}$ $\mathrm{C} / \mathrm{g} /$ day, $0.084 \mathrm{~g} \mathrm{C} / \mathrm{g}$ and 1.96. $\frac{d D W}{d t}$ (g/day) is the growth rate of dry mesocarp.

Phloem flux of carbon into the fruit $\left(\frac{d M p h}{d t}\right)$ is calculated as follows:

$$
\frac{d M p h}{d t}=\sigma_{d w} \frac{d D W}{d t}+\frac{d M r e}{d t}
$$

where $\sigma_{d w}$ is the carbon concentration of the mesocarp ( $\mathrm{g} \mathrm{C} / \mathrm{g} D W$ ) that is assumed to be constant, $0.445 \mathrm{~g} \mathrm{C} / \mathrm{g} D W$ (Génard \& Souty 1996), during the final stage of fruit growth.

\section{Model parameterization}

Daily fresh $(F W)$ and dry mesocarp weight $(D W)$ were estimated from the measured values by regression (Bates \& Chambers 1992). The cumulative data for each cultivar from 2005 and 2007 was subjected to the SUGARb model, and the parameter values were estimated by non-linear least squares.

\section{Comparisons of models}

F-test and likelihood ratio test (LR) were used to compare the SUGAR model and the SUGARb model, in terms of fit quality. The SUGAR model included five parameters, $k_{1,1}, k_{1,2}, k_{2}, k_{3}$ and $k_{4}$, and the SUGARb model included the same five parameters with two additional ones, $k_{5}$ and $k_{6}$. The F-test was performed by analysis of variance (S-Plus 'ANOVA' function), and it identified significant pairwise differences between the models $(P<0.05)$. The LR test followed a $\chi^{2}$ distribution $(P<0.05)$ with the formula: 


$$
L R=n \ln \frac{R S S_{\text {SUGAR }}}{R S S_{S U G A R b}}
$$

where $n$ is the observation number (sample size), $R R S_{S U G A R}$ and $R R S_{S U G A R b}$ are, respectively, the residual sum of squares of the SUGAR model and the SUGARb model.

\section{RESULTS}

\section{Characteristics of glucose and fructose concentrations}

The characteristic G:F ratio for a given cultivar was independent of year and developmental stage (Fig. 2). Glucose and fructose concentrations for cvars Shanyibaitao, Yanhong and Ganghanbai were quite close to each other throughout the final rapid growth stage (74-85 DAB to maturity) with G:F ratios ranging from 0.8-1.5. For cvars Zhanghuang 7, Long 246 and Linbai 7, G:F generally ranged from $1.5-7.8$

\section{Parameterization and comparisons of parameter values}

During the parameterization process of the SUGARb model, estimated values of $k_{6}$ (net conversion rate of fructose to glucose) were not significantly different from zero (data not shown). This indicated that hexosephosphate interconversion by PGI was in equilibrium in all the studied cultivars. Consequently, $k_{6}$ values were set to zero for all the cultivars and the other six parameters were estimated again (Table 1).

Differences in $k_{1,1}$ and $k_{1,2}$ values were found between cultivars in each G:F group. However, no specific characteristics appeared between normal and high G:F groups: 
$k_{1,1}$ of normal G:F cultivars (0.084-0.133/day) was either higher than or similar to that of high G:F cultivars (0.054-0.086/day), while $k_{1,2}$ of the three normal G:F cultivars (68-71 DAB) were intermediate compared to those of high G:F cultivars $(57-80$ DAB). The relative rates of sucrose transformation to glucose and fructose $\left(k_{l}(t)\right)$, expressed by $k_{1,1}$ and $k_{1,2}$, also showed no differences between normal and high G:F groups, and it decreased with fruit development and approached zero at maturity (not shown).

The relative rates of sorbitol transformation to glucose $\left(k_{2}\right)$ and to fructose $\left(k_{3}\right)$ showed little differences for normal G:F cultivars, ranging from $0.128-0.215 /$ day, which indicated similar conversion rates of sorbitol to glucose and fructose. For high G:F cvars Zhanghuang 7 and Long 246, $k_{2}$ values were 0.268 /day and 0.166 /day, while $k_{3}$ values were near to zero. For high G:F cvar Linbai $7, k_{2}(0.197 /$ day $)$ and $k_{3}$ (0.132/day) showed no obvious difference.

The utilization rates of glucose $\left(k_{4}\right)$ and fructose $\left(k_{5}\right)$ for normal G:F cultivars were similar, and $k_{4}$ or $k_{5}$ was about $1.1-1.3$ times that of $k_{5}$ or $k_{4} . k_{4}$ for high G:F cvars Long 246 and Linbai 7 (2.77 and 2.21, respectively) were roughly in the range of normal G:F cultivars (2.28-2.98), while $k_{5}(4.80-6.23)$ were obviously higher than those of normal G:F cultivars (1.72-2.91), being 1.7-2.8 times that of $k_{4}$. In contrast, for high G:F cvar Zhanghuang 7, $k_{4}$ and $k_{5}$ were similar.

\section{Comparisons of models}


Using F-test and LR test, there was no significant difference in goodness of fit between the SUGAR and the SUGARb models for each cultivar (Table 2), which indicted that adding new pathways (represented by parameters $k_{5}$ and $k_{6}$ ) to extend the SUGAR model did not change the prediction quality of sugar accumulation for any of the cultivars.

\section{Simulated seasonal sugar concentrations}

Although standard errors of the parameters for the SUGARb model were rather high in some cases (Table 1), the simulated seasonal variations in sugars matched well with experimental data for normal and high G:F cultivars (Fig. 3). Simulated curves of seasonal variations in sugars were well within the measured data in 2005 and 2007. The SUGARb model was able to simulate seasonal variations in sugar concentrations for both normal and high G:F cultivars, and reproduced accurately the difference in glucose and fructose concentrations during the season. The main discrepancies between measured and simulated seasonal variations appeared in 2007: sorbitol concentrations were underestimated, and glucose and fructose concentrations were overestimated at the beginning of the experimental period and underestimated at the end, especially for normal G:F cultivars.

\section{DISCUSSION}

In the present study, the SUGAR model of Génard et al. (2003) was extended (SUGARb model) to investigate the mechanisms responsible for different G:F ratios 
in peach fruit. The SUGARb model includes two additional parameters $\left(k_{5}\right.$ and $\left.k_{6}\right)$. Though the SUGARb model does not improve prediction quality, it is more generic and enlarges the utility and range of the SUGAR model. The SUGAR model assumed $k_{4}=k_{5}$ and $k_{6}=0$. According to the results of the parameter estimation using the SUGARb model, $k_{6}$ can be assumed equal to zero whatever the cultivar and the G:F ratio. However, the assumption that $k_{4}=k_{5}$ was found to be acceptable for the normal G:F cultivars and for the high G:F cvar Zhanghuang 7, but not for the other two high G:F cvars Long 246 and Linbai 7. Therefore, the generic SUGARb model can be used to investigate the effective mechanisms responsible for different G:F ratio, whereas the SUGAR model assumes that only one strategy is possible.

The SUGARb model simulated seasonal variations in sugar concentrations for both normal and high G:F cultivars well, although some discrepancies were observed. The proportion of sucrose in the phloem $(\lambda \mathrm{ph})$ was supposed constant in the study during the final rapid growth stage. However, it has been reported to fluctuate between 0.23 and 0.54 for the peach rootstock GF305 in response to growth conditions (e.g. water stress) (Escobar-Gutiérrez \& Gaudillére 1997; Escobar-Gutiérrez et al. 1998; Lo Bianco et al. 2000), and has been estimated at 0.35 for peach cvar Suncrest (Génard et al. 2003) and 0.26 for cvar RedHaven (Nadwodnik \& Lohaus 2008). The sucrose-sorbitol ratio in leaves has also been reported to vary with genotype (Escobar-Gutiérrez \& Gaudillére 1994), which could influence the proportion of sucrose in the phloem. No information is available about sugars in the phloem for the cultivars in the present study, or their evolution during fruit 
development. The maximum, median and minimum $\lambda$ ph values $(0.23,0.35$ and 0.54$)$ were taken in the above references, and it was found that the results of parameterization were comparable with $\lambda$ ph values of 0.35 and 0.54 , whatever the cultivars. In contrast, solving model parameterization using a low $\lambda$ ph value $(0.23)$ was not always possible (data not shown). Fit quality for models with $\lambda$ ph 0.35 and 0.54 were similar, but better for more cultivars with $\lambda$ ph 0.54 . Thus, $\lambda$ ph 0.54 was chosen for all the cultivars during the final rapid fruit growth stage. Nevertheless, the variation of $\lambda$ ph among cultivars and with fruit development would have to be considered in future modelling which might improve simulations.

In the SUGARb model, the net sucrose transformation to glucose and fructose $\left(k_{1}(t)\right)$, together with the proportion of sucrose in the phloem $(\lambda \mathrm{ph})$, determined sucrose accumulation. As $\lambda$ ph is supposed to be constant during the final rapid growth stage of the fruit, the decrease in $k_{l}(t)$ indicated that accumulation of sucrose in peach mesocarp approaching maturity is mostly due to a decrease in the activities of all enzymes (acid invertase, neutral invertase and sucrose synthase) related to sucrose breakdown (Vizzotto et al. 1996; Lo Bianco et al. 1999). Since $k_{l}(t)$ differed according to cultivar but not to G:F status (as mentioned above), different G:F ratios in peach mesocarp would not be related to sucrose accumulation.

The relative rates of sorbitol transformation to glucose $\left(k_{2}\right)$ and to fructose $\left(k_{3}\right)$ showed considerable differences for high G:F cvars Zhanghuang 7 and Long 246. This was in accordance with the report of Kanayama et al. (2005), showing that $\mathrm{NAD}^{+}-\mathrm{SDH}$ activities, which catalyzes sorbitol to fructose formation, were always 
lower in the two high G:F peach cvars Nagano yaseito Early and Notozairaito No. 2 than in the two normal G:F peach cvars Akatsuki and Kawanakajima hakuto. This led the authors to suggest that differences in the capacity for fructose formation by $\mathrm{NAD}^{+}-\mathrm{SDH}$ might be an important factor controlling fructose concentration in peach fruit. However, results reported in the present study for the high G:F cvar Linbai 7 did not show obvious difference between $k_{2}$ and $k_{3}$. This indicated that a low relative rate of sorbitol conversion to fructose could result in low fructose in some high G:F cultivars but not in some other high G:F cultivars, such as cvar Linbai 7.

The utilization rate of fructose $\left(k_{5}\right)$ was obviously higher than the utilization rate of glucose $\left(k_{4}\right)$ for high G:F cvars Long 246 and Linbai 7, while $k_{4}$ and $k_{5}$ were similar for high G:F cvar Zhanghuang 7. Glucose and fructose are transformed by HK and FK, respectively, to Glu6P and Fru6P, which are used for glycolysis. Kanayama et al. (2005) showed that the high G:F cvar Naganoyaseito Early had a higher FK activity than normal G:F cultivars, while another high G:F cultivar, cvar Notozairaito NO. 2, had a lower FK activity than normal G:F cultivars. Consequently, high relative utilization rate of fructose was also not a universal pathway resulting in low fructose for all the high G:F cultivars.

So far, only Kanayama et al. (2005) has made a contrasting study of normal vs high G:F cultivars, and information on glucose and fructose utilization and the conversion between them during peach fruit development is still limited. High G:F ratios were also reported in some other species, for example tomato, pear and apple, though all of them usually displayed higher fructose than glucose concentrations. Dai 
et al. (2002) found that a reduction in FK activity could explain higher fructose in tomato species (L. hirsutum). Suzuki et al. (2001) suggested that both low FK and high $\mathrm{NAD}^{+}-\mathrm{SDH}$ activities contribute to fructose accumulation in Japanese pear (Pyrus pyrifolia Nakai). Schaffer et al. (1999) and Suzuki et al. (2001) considered that phosphoglucose isomerase was unlikely to be responsible for the regulation of fructose levels in these two species. However, hexosephosphate interconversion was not in equilibrium, and phosphoglucomutase (PGM), which interconverts Glu6P and glucose-1-phosphate (Glu1P), was also involved in the regulation of carbon partitioning (Berüter 2004). Therefore, though a lower formation rate of fructose $\left(k_{3}(t)\right)$ than glucose $\left(k_{2}(t)\right)$ from sorbitol and/or a higher utilization rate of fructose $\left(k_{5}(t)\right)$ than that of glucose $\left(k_{4}(t)\right)$ might be preferential strategies for forming high G:F ratios, as shown in the present study from modelling, hexosephosphate interconversion $\left(k_{6}\right)$ cannot be ignored and needs to be tested using a wider genetic range.

Consequently, more enzymatic and biochemical studies are necessary to elucidate further the three pathways. In addition, studies on other high G:F genotypes from diverse origins, for example Chinese wild species, Prunus kansuensis and P. ferganensis, would be useful to explore the potential variability of the mechanisms that regulate glucose and fructose accumulation in peach fruit. In the near future, computing the relative contribution of each sugar to sweetness during fruit development through the SUGARb model looks promising and could allow dynamic evaluation of fruit quality as it develops. Moreover, the present models may be useful 
for understanding hexose accumulation in other species with differing glucose and fructose concentrations, i.e. apple and pear with higher fructose than glucose concentrations, and apricot with lower fructose than glucose concentrations.

The authors thank Q. Jiang for his offer of peach germplasm, X. H. Jin for temperature data, J. Niu for her assistance in sugar measurements, and D. D. Archbold (Department of Horticulture, University of Kentucky, USA) for improving English language. This research was funded by National Natural Science Foundation of China (NSFC 30600418).

\section{REFERENCES}

BAtes, D. M. \& Chambers, J. M. (1992). Nonlinear models. In Statistical Models in $S$ (Eds J. M. Chambers \& T. J. Hastie), pp. 421-454. New York: Chapman \& Hall.

BERÜTER, J. (2004). Carbohydrate metabolism in two apple genotypes that differ in malate accumulation. Journal of Plant Physiology 161, 1011-1029.

Borsani, J., Budde, C. O., Porrini, L., Lauxmann, M. A., Lombardo, V. A., Murray, R., Andreo, C. S., Drincovich, M. F. \& Lara, M. V. (2009). Carbon metabolism of peach fruit after harvest: changes in enzymes involved in organic acid and sugar level modifications. Journal of Experimental Botany 60, $1823-1837$.

Chapman, G. W. Jr. \& Horvat, R. J. (1990). Changes in nonvolatile acids, sugars, 
pectin and sugar composition of pectin during peach (cv. Monroe) maturation. Journal of Agriculture and Food Chemistry 38, 383-387.

Dai, N., German, M. A., Matsevitz, T., Hanael, R., Swartzberg, D., Yeselson, Y., Petreikov, M., Schaffer, A. A. \& Granot, D. (2002). LeFrK2, the gene encoding the major fructokinase in tomato fruits, is not required for starch biosynthesis in developing fruits. Plant Science 162, 423-430.

DeJong, T. M., Doyle, J. F. \& DAY, K. R. (1987). Seasonal patterns of reproductive and vegetative sink activity in early and late maturing peach (Prunus persica) cultivars. Physiologia Plantarum 71, 83-88.

DeJong, T. M. \& GoudriaAn, J. (1989). Modeling peach fruit growth and carbohydrate requirements: reevaluation of the double-sigmoid growth pattern. Journal of the American Society for Horticultural Science 114, 800-804.

Dirlewanger, E., Moing, A., Rothan, C., Svanella, L., Pronier, V., Guye, A., Plomion, C. \& Monet, R. (1999). Mapping QTLs controlling fruit quality in peach (Prunus persica (L.) Batsch). Theoretical and Applied Genetics 98, 18-31.

Doty, T. E. (1976). Fructose sweetness: a new dimension. Cereal Foods World 21, $62-63$.

Escobar-GutiÉRrez, A. J. \& GAudillère, J. P. (1994). Variability in sorbitol:sucrose ratios in mature leaves of different peach cultivars. Journal of the American Society for Horticultural Science 119, 321-324.

Escobar-GutiÉrrez, A. J. \& Gaudillère, J. P. (1997). Carbon partitioning in source leaves of peach, a sorbitol-synthesizing species, is modified by 
photosynthetic rate. Physiologia Plantarum 100, 353-360.

Escobar-Gutiérrez, A. J., Zipperlin, B., Carbonne, F., Moing, A. \& Gaudillère, J. P. (1998). Photosynthesis, carbon partitioning and metabolite content during drought stress in peach seedlings. Australian Journal of Plant Physiology 25, $197-205$.

Esti, M., Messia, M. C., Sinesio, F., Nicotra, A., Conte, L., la Notte, E. \& PALlESCHI, G. (1997). Quality evaluation of peaches and nectarines by electrochemical and multivariate analyses: relationships between analytical measurements and sensory attributes. Food Chemistry 60, 659-666.

GÉnARD, M., Lescourret, F., Gomez, L. \& Habib, R. (2003). Changes in fruit sugar concentrations in response to assimilate supply, metabolism and dilution: a modeling approach applied to peach fruit (Prunus persica). Tree Physiology 23, 373-385.

Génard, M., Lescourret, F., Reich, M., Albagnac, G. \& Audergon, J. M. (2006). Modeling the apricot sugar contents in relation to fruit growth. Acta Horticulturae 701, 517-522.

GÉnARD, M. \& SOUTY, M. (1996). Modeling the peach sugar contents in relation to fruit growth. Journal of the American Society for Horticultural Science 121, $1122-1131$.

Grechi, I., Hilgert, N., GÉnARd, M. \& Lescourret, F. (2008). Assessing the peach fruit refractometric index at harvest with a simple model based on fruit growth. Journal of the American Society for Horticultural Science 133, 178-187. 
Kanayama, Y., Kogawa, M., Yamaguchi, M. \& Kanahama, K. (2005). Fructose content and the activity of fructose-related enzymes in the fruit of eating-quality peach cultivars and native-type peach cultivars. Journal of the Japanese Society for Horticultural Science 74, 431-436.

Kortstee, A. J., Appeldoorn, N. J. G., Oortwijn, M. E. P. \& Visser, R. G. F. (2007). Differences in regulation of carbohydrate metabolism during early fruit development between domesticated tomato and two wild relatives. Planta 226, 929-939.

Kulp, K., LoRenZ, K. \& Stone, M. (1991). Functionality of carbohydrates ingredients in bakery products. Food Technology 45, 136-142.

Lo Bianco, R., Rieger, M. \& Sung S. S. (1999). Carbohydrate metabolism of vegetative and reproductive sinks in the late-maturing peach cultivar 'Encore'. Tree Physiology 19, 103-109.

Lo BiAnCO, R., Rieger, M. \& Sung, S. S. (2000). Effect of drought on sorbitol and sucrose metabolism in sinks and sources of peach. Physiologia Plantarum 108, $71-78$.

Moing, A., Carbonne, F., Rashad, M. H. \& Gaudillère, J. P. (1992). Carbon fluxes in mature peach leaves. Plant Physiology 100, 1878-1884.

Moing, A., Carbonne, F., Zipperlin, B., Svanella, L. \& Gaudillere, J. P. (1997). Phloem loading in peach: symplastic or apoplastic? Physiologia Plantarum 101, $489-496$.

Morandi, B., Grappadelli, L. C., Rieger, M. \& Lo Bianco, R. (2008). 
Carbohydrate availability affects growth and metabolism in peach fruit. Physiologia Plantarum 133, 229-241.

Moriguchi, T., SANADA, T. \& YAMAKI, S. (1990a). Seasonal fluctuations of some enzymes relating to sucrose and sorbitol metabolism in peach fruit. Journal of the American Society for Horticultural Science 115, 278-281.

Moriguchi, T., Ishizawa, Y. \& SANADA, T. (1990b). Differences in sugar composition in Prunus persica fruit and the classification by the Principal Component Analysis. Journal of the Japanese Society for Horticultural Science 59, 307-312.

NADWODNIK, J. \& LOHAUS, G. (2008). Subcellular concentrations of sugar alcohols and sugars in relation to phloem translocation in Plantago major, Plantago maritime, Prunus persica, and Apium graveolens. Planta 227, 1079-1089.

NiU, J., ZhaO, J.,B., Wu, B. H., LI, S. H., LiU, G. J. \& JiAnG, Q. (2006). Sugar and acid contents in peach and nectarine derived from different countries and species. Acta Horticulturea Sinica 33, 6-11.

PANGBORN, R. M. (1963). Relative taste of selected sugars and organic acids. Journal of Food Science 28, 726-733.

Quilot, B., Génard, M., Kervella, J. \& Lescourret, F. (2004). Analysis of genotypic variation in fruit flesh total sugar content via an ecophysiological model applied to peach. Theoretical and Applied Genetics 109, 440-449.

Robertson, J. A., Horvat, R. J., Lyon, B. G., Meredith, F. I., Senter, S. D. \& OKIE, W. R. (1990). Comparison of quality characteristics of selected yellow- 
and white-fleshed peach cultivars. Journal of Food Science 55, 1308-1311.

RoHwer, J. M. \& BothA, F.C. (2001). Analysis of sucrose accumulation in the sugar cane culm on the basis of in vitro kinetic data. Biochemical Journal 358, $437-445$.

Schaffer, A. A., Petreikov, M., Miron, D., Fogelman, M., Spiegelman, M., Bnei-Moshe, Z., Shen, S., Granot, D., Hadas, R., Dai, N., Levin, I., Bar, M., Friedman, M., Pilowsky, M., GilboA, N. \& Chen, L. (1999). Modification of carbohydrate content in developing tomato fruit. HortScience 34, 1024-1027.

Suzuki, Y., Odanaka, S. \& Kanayama, Y. (2001). Fructose content and fructose-related enzyme activity during the fruit development of apple and Japanese pear. Journal of the Japanese Society for Horticultural Science 70, $16-20$.

Uys, L., Botha, F. C., Hofmeyr, J. S. \& Rohwer, J. M. (2007). Kinetic model of sucrose accumulation in maturing sugarcane culm tissue. Phytochemistry 68, $2375-2392$.

Vizzotto, G., Pinton, R., Varanini, Z. \& Costa, G. (1996). Sucrose accumulation in developing peach fruit. Physiologia Plantarum 96, 225-230.

Wu, B. H., Quilot, B., Kervella, J., GÉnard, M. \& Li, S. H. (2003). Analysis of genotypic variation of sugar and acid contents in peaches and nectarines through the Principle Component Analysis. Euphytica 132, 375-384. 
Version définitive du manuscrit publié dans / Final version of the manuscript published in : The Journal of Agricultural Science, 2011, DOI: 101017/S0021859611000438

Table 1. Parameter values (+S.E.) for normal G:F cvs. Shanyibaitao (Shan), Yanhong (Yan) and Gangshanbai (Gang), and high G:F cvs. Zhanghuang 7 (Zhang), Long 246 (Long) and Linbai 7 (Lin)

\begin{tabular}{|c|c|c|c|}
\hline \multirow[t]{3}{*}{ Parameter } & \multicolumn{3}{|c|}{ Estimated value (s.e.) } \\
\hline & \multicolumn{3}{|c|}{ Normal G:F peach cultivars } \\
\hline & Shan & Yan & Gang \\
\hline$k_{1,1}$ & $0.08(0.008)$ & $0.13(0.018)$ & $0.11(0.014)$ \\
\hline$k_{1,2}$ & $68(3)$ & $71(3)$ & $68(3)$ \\
\hline$k_{2}$ & $0.14(0.063)$ & $0.18(0.077)$ & $0.13(0.045)$ \\
\hline$k_{3}$ & $0.16(0.064)$ & $0.22(0.079)$ & $0.13(0.045)$ \\
\hline$k_{4}$ & $3.0(1.35)$ & $2.3(1.29)$ & $2.3(0.97)$ \\
\hline \multirow[t]{3}{*}{$k_{5}$} & $2.7(1.17)$ & $2.9(1.29)$ & $1.7(0.85)$ \\
\hline & \multicolumn{3}{|c|}{ High G:F peach cultivars } \\
\hline & Zhang & Long & Lin \\
\hline$k_{1,1}$ & $0.05(0.006)$ & $0.09(0.010)$ & $0.08(0.006)$ \\
\hline$k_{1,2}$ & $57(5)$ & $67(4)$ & $80(2)$ \\
\hline$k_{2}$ & $0.27(0.094)$ & $0.17(0.089)$ & $0.20(0.055)$ \\
\hline$k_{3}$ & $0.04(0.088)$ & $0.10(0.087)$ & $0.13(0.053)$ \\
\hline$k_{4}$ & $4.5(1.73)$ & $2.8(1.87)$ & $2.2(0.74)$ \\
\hline$k_{5}$ & $4.5(3.97)$ & $4.8(3.63)$ & $6.2(1.95)$ \\
\hline
\end{tabular}


Version définitive du manuscrit publié dans / Final version of the manuscript published in : The Journal of Agricultural Science, 2011, DOI: 101017/S0021859611000438

Table 2. F-test and Likelihood ratio (LR) test between the SUGAR and SUGARb models for normal G:F cvs. Shanyibaitao (Shan), Yanhong (Yan) and Gangshanbai (Gang), and high G:F cvs. Zhanghuang 7 (Zhang), Long 246 (Long) and Linbai 7 (Lin)

\begin{tabular}{ccccccc}
\hline \hline & \multicolumn{2}{c}{ Normal G:F peach cultivars } & \multicolumn{2}{c}{ High G:F peach cultivars } \\
& Shan & Yan & Gang & Zhang & Long & Lin \\
\hline F value of F-test & $0.11(\mathrm{~ns})$ & $0.03(\mathrm{~ns})$ & $0.19(\mathrm{~ns})$ & $0.44(\mathrm{~ns})$ & $0.40(\mathrm{~ns})$ & $0.82(\mathrm{~ns})$ \\
Likelihood ratio & $0.24(\mathrm{~ns})$ & $0.06(\mathrm{~ns})$ & $0.40(\mathrm{~ns})$ & $0.91(\mathrm{~ns})$ & $0.83(\mathrm{~ns})$ & $1.73(\mathrm{~ns})$ \\
\hline \hline
\end{tabular}

ns: no significant difference between the SUGAR and SUGARb models at $P<0.05$. 


\section{Figure legends}

Fig. 1. Carbon metabolism in fruit. (a) A simplified representation of the pathways. The enzymes which catalyse the numbered steps are: 1) NAD-dependent sorbitol dehydrogenase (NAD; 2) sorbitol-6-phosphate dehydrogenase; 3) sorbitol oxidase; 4) acid invertase, neutral invertase; 5) sucrose synthase; 6) fructokinase; 7) hexokinase; 8) UDPGPPase; 9) phosphoglucose isomerase; 10) phosphoglucomutase; 11) phosphofructokinase; 12) phosphofructophosphotransferase; 13) glucose-6-phosphate degydrogenase; 14) ADPGPPase. (b) Diagram of the modified SUGAR model (SUGARb). $\lambda$ ph and $1-\lambda$ ph are the proportions of carbon in the form of sucrose and sorbitol, respectively, in the phloem unloaded into fruit. Parameters: $k_{l}(t)$ is the relative rate of net sucrose transformation to glucose and fructose, $k_{2}(t)$ is net sorbitol transformation to glucose, $k_{3}(t)$ is net sorbitol transformation to fructose, $k_{4}(t)$ and $k_{5}(t)$ is net glucose and fructose transformation to other compounds, and $k_{6}(t)$ is net fructose transformation to glucose.

Fig. 2. Glucose and fructose concentrations in the mesocarp of normal G:F cvars Shanyibaitao (Shan), Yanhong (Yan) and Gangshanbai (Gang), and high G:F cvars Zhanghuang 7 (Zhang), Long 246 (Long) and Linbai 7 (Lin). Data are measured values from fruits sampled every 1-2 weeks during the final rapid growth stage. The numbers outside the right $y$-axis are glucose-to-fructose concentration ratios. 
Version définitive du manuscrit publié dans / Final version of the manuscript published in : The Journal of Agricultural Science, 2011, DOI: 101017/S0021859611000438

Fig. 3. Observed (triangles) and simulated (lines) seasonal variations of sugar concentrations for normal G:F cvs. Shanyibaitao, Yanhong and Gangshanbai, and high G:F cvs. Zhanghuang 7, Long 246 and Linbai 7 using the SUGARb model. 
Version définitive du manuscrit publié dans / Final version of the manuscript published in : The Journal of Agricultural Science, 2011, DOI: 101017/S0021859611000438

(a)

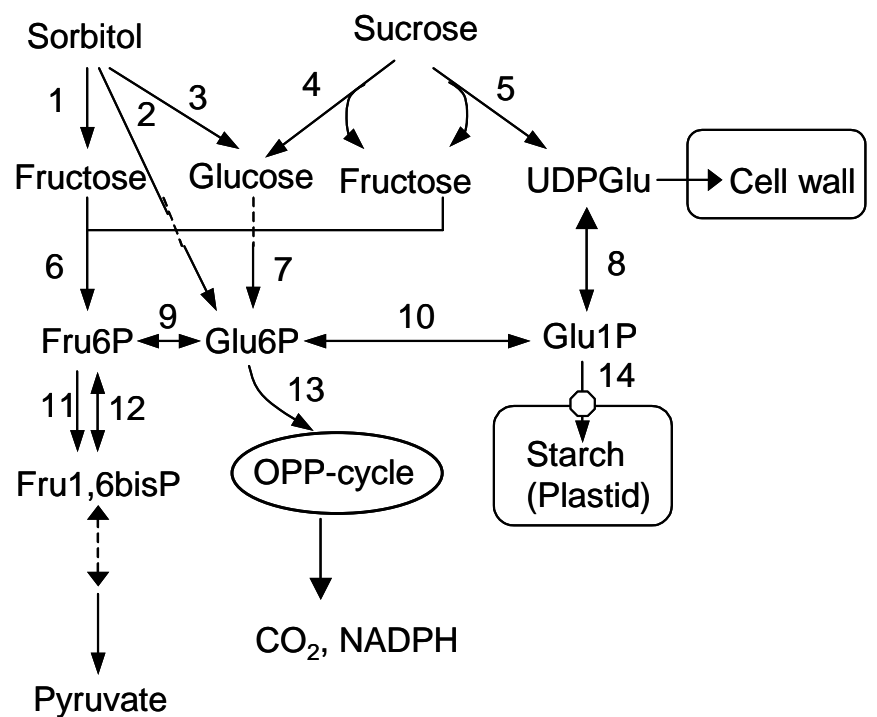

(b)
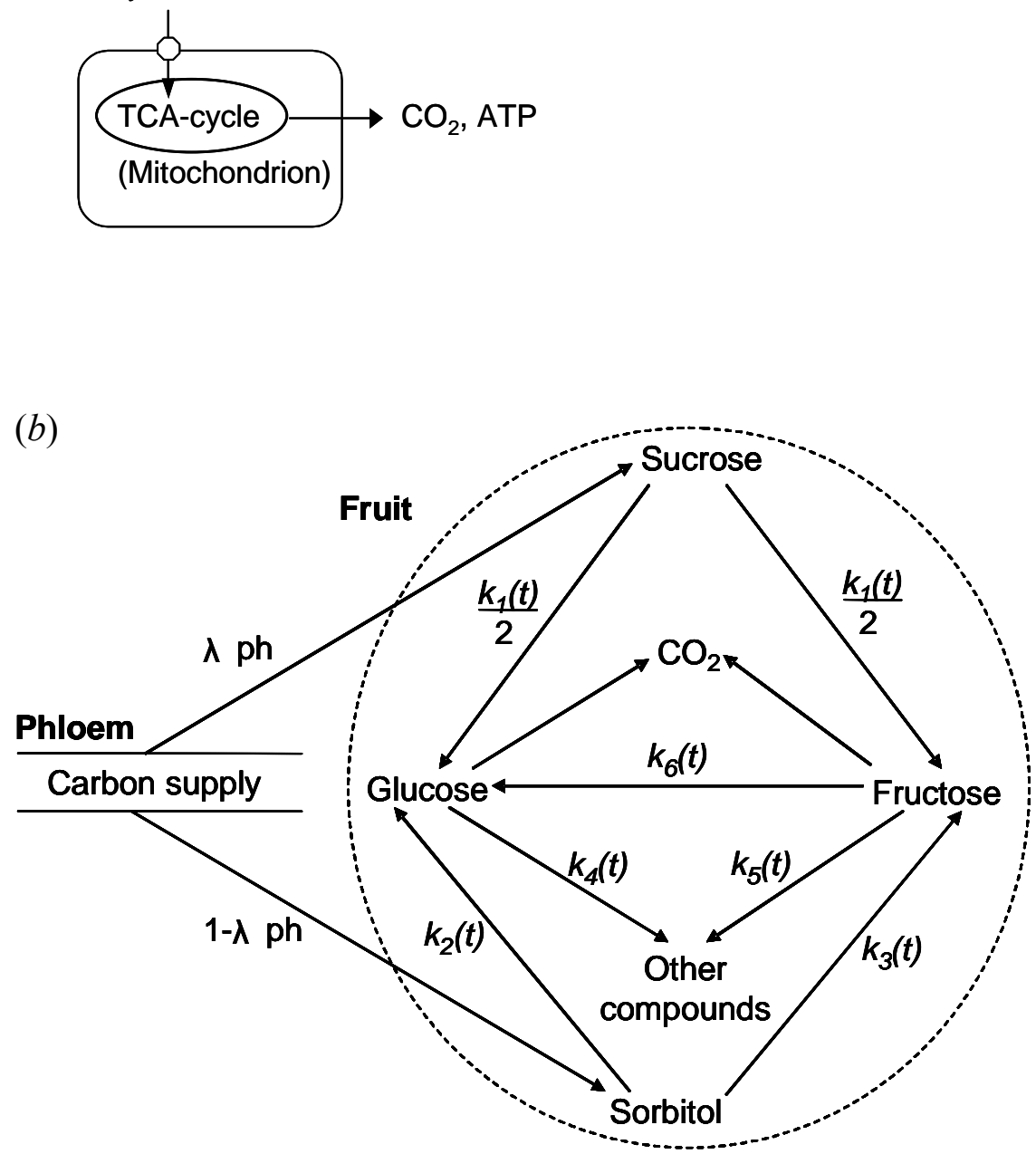

Fig. 1. 
Version définitive du manuscrit publié dans / Final version of the manuscript published in : The Journal of Agricultural Science, 2011, DOI: 101017/S0021859611000438

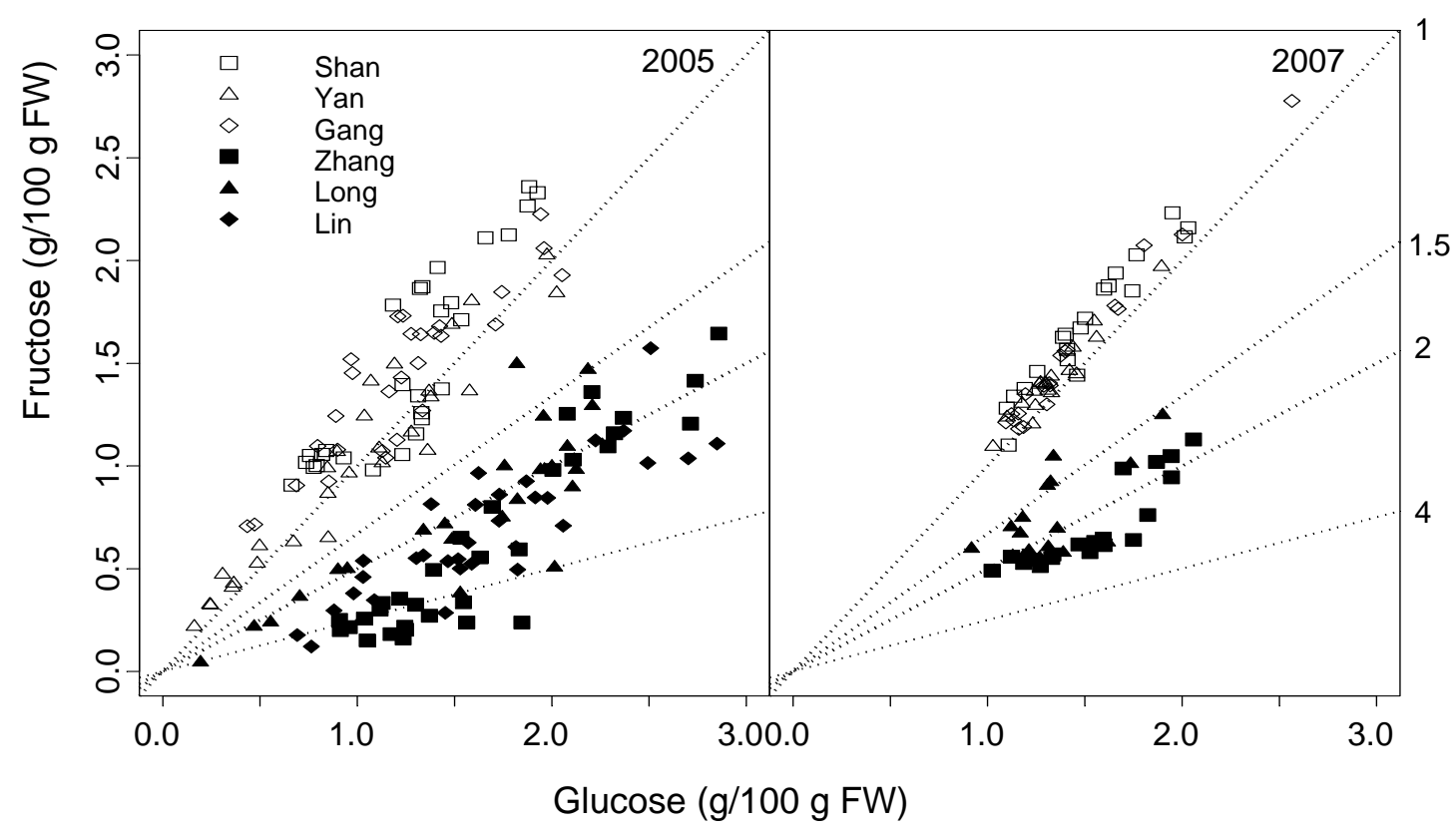

Fig. 2. 


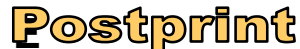

Version définitive du manuscrit publié dans / Final version of the manuscript published in : The Journal of Agricultural Science, 2011, DOI: 101017/S0021859611000438

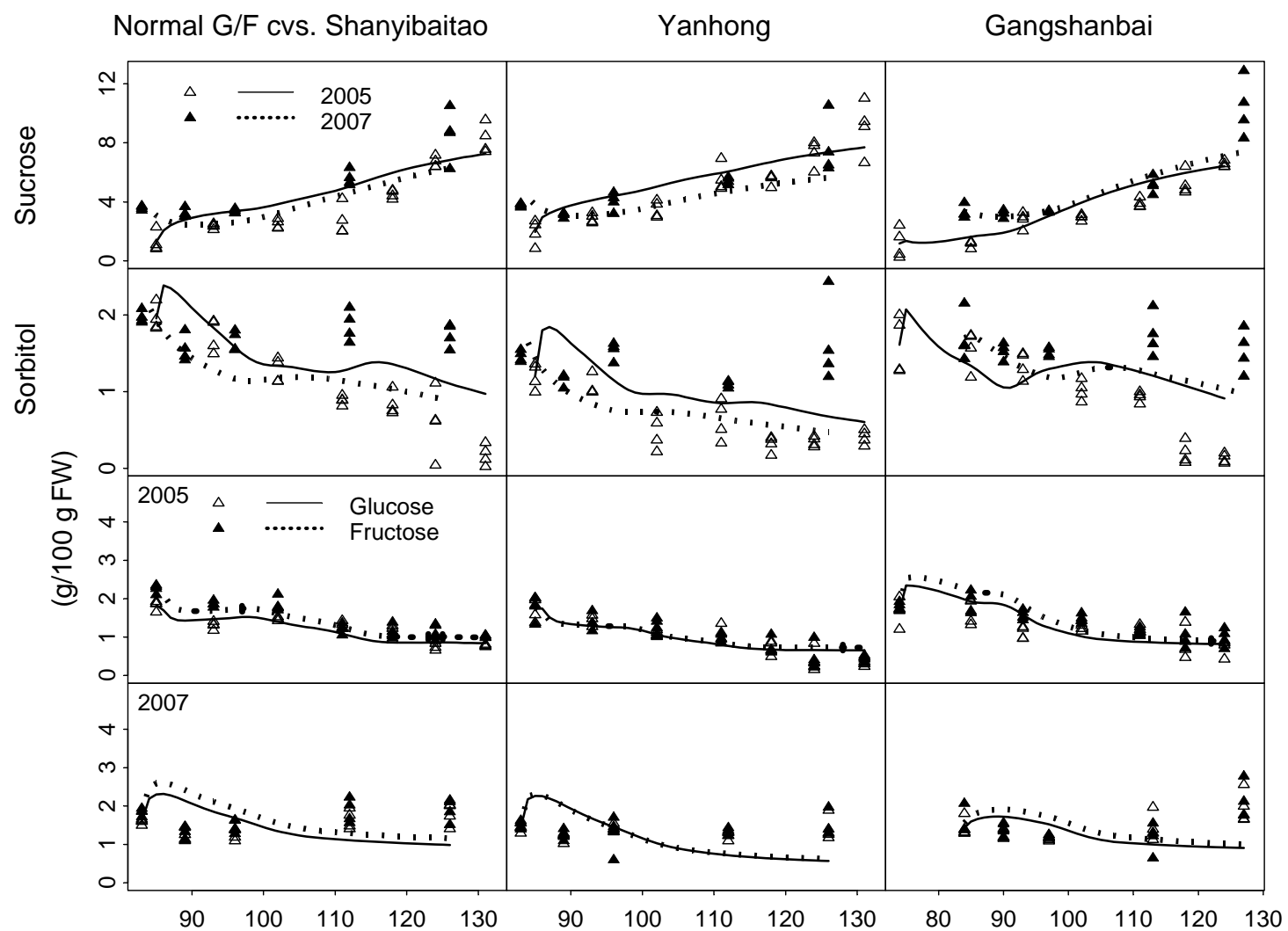

High G/F cvs. Zhanghuang 7

Long 246

Linbai 7

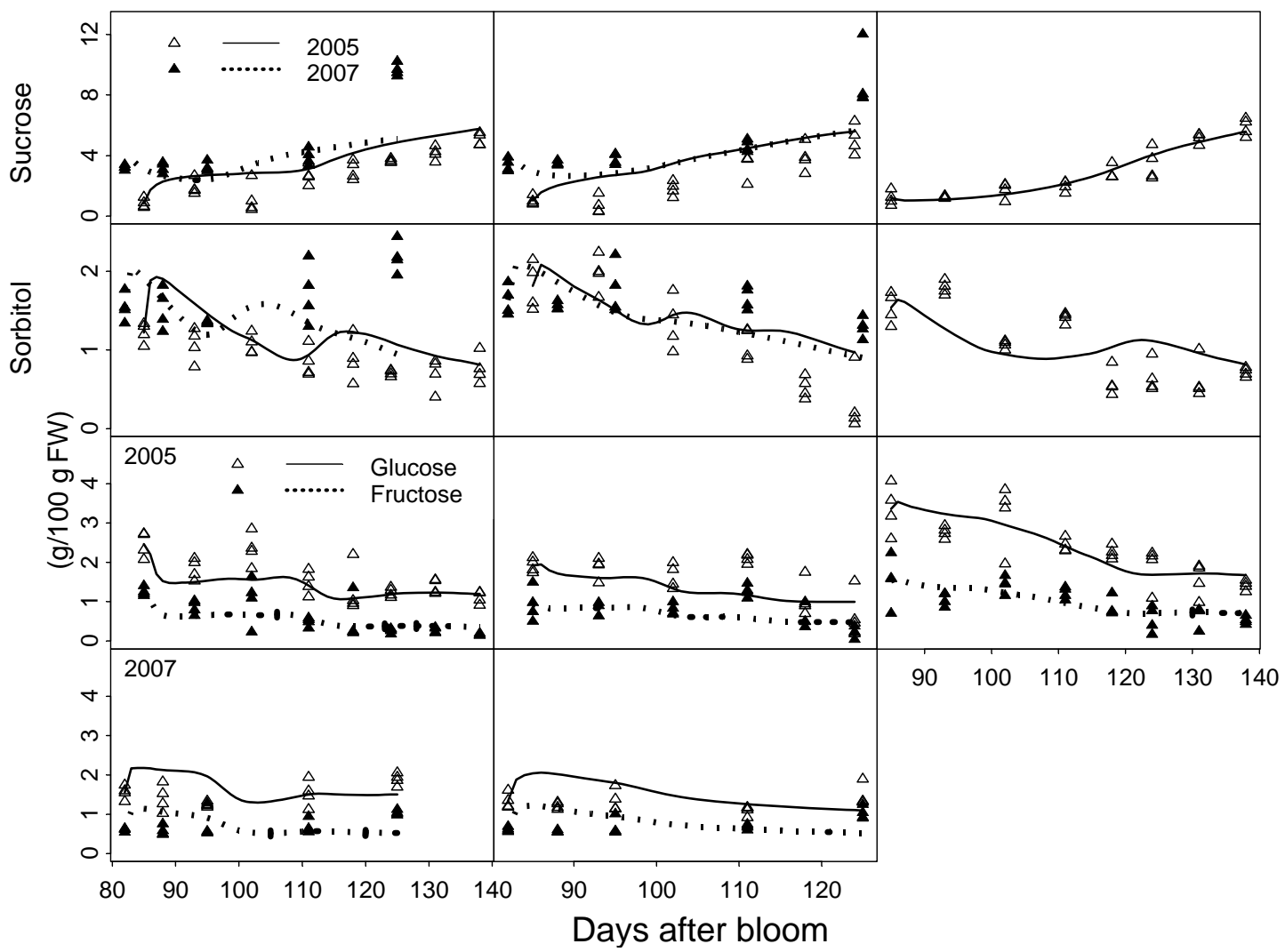

Fig. 3. 